\title{
Lodo gerado em Estação de Tratamento de Água: Avaliação preliminar da toxicidade em plantas de milho
}

Sludge generated in a water treatment plant: Preliminary assessment of toxicity in corn plants

\author{
G. A. Bitencourt*; J. P. Apolari; G. de Souza; R. T. R. Monteiro \\ Centro de Energia Nuclear na Agricultura/CENA, Universidade de São Paulo, 13400-970, Piracicaba-SP, Brasil
}

*gislaynebitencourt@gmail.com

(Recebido em 11 de setembro de 2020; aceito em 07 de dezembro de 2020)

\begin{abstract}
O lodo é o principal resíduo gerado em Estação de Tratamento de Água (ETA), é oriundo do processo de potabilização da água, apresenta grande concentração de sólidos e, elementos químicos como o alumínio e ferro. Por esse motivo, o mesmo não pode ser descartado nos mananciais, necessitando de alternativas ambientalmente seguras para uma destinação adequada. O objetivo com esta pesquisa foi avaliar a toxicidade do lodo gerado em ETA associado ao bagaço e vinhaça de cana-de-açúcar na germinação e crescimento inicial de Zea mays L. A compostagem do lodo foi realizada por 60 dias, com uma mistura de bagaço e vinhaça inoculado com Pleurotus sajor-caju. O composto foi incorporado ao solo nas doses de 0; 1; 10 e 100 de composto/solo $\left(\mathrm{g} \mathrm{kg}^{-1}\right)$. Foram semeadas 10 sementes de Z. mays híbrido 2B433Hx da Dow Agrosciences, após sete dias foi realizado o desbaste deixando cinco plântulas em cada vaso. O delineamento experimental utilizado foi o inteiramente casualizado com quatro repetições. Após 21 dias de cultivo foram avaliadas: porcentagem de emergência; índice de velocidade de emergência; comprimento e massa seca de raízes e parte aérea. A dose de $100 \mathrm{~g} \mathrm{~kg}^{-1}$ promoveu reduções no comprimento de parte aérea e sintomas de deficiência nutricional ocasionados pelo excesso de alumínio, ferro e sódio no lodo. Para o uso seguro, recomendamos a dose de $10 \mathrm{~g} \mathrm{~kg}^{-1}$ do composto de lodo de ETA.
\end{abstract}

Palavras-chave: fitotoxicidade, lodo de água, reaproveitamento

Sludge is the main waste generated in the water treatment plants (WTP), is from the water potabilization process, has a high concentration of solids and chemical elements such as aluminum and iron. For this reason, it cannot be discarded in water sources, requiring environmentally safe alternatives for proper disposal. The objective of this research was to evaluate the toxicity of the sludge generated in WTP associated with sugarcane bagasse and vinasse in the germination and initial growth of Zea mays L. The composting of the sludge was carried out for 60 days, with a mixture of bagasse and vinasse inoculated with Pleurotus sajorсаju. The compost was incorporated in the soil at doses of $0 ; 1 ; 10$ and 100 compost/soil $\left(\mathrm{g} \mathrm{kg}^{-1}\right)$. Ten seeds of Z. mays hybrid 2B433Hx from Dow Agrosciences were sown. After seven days, thinning was carried out, leaving five seedlings in each pot. The experimental design used was completely randomized with four replications. After 21 days of cultivation, the following were evaluated: percentage of emergency; emergency speed index; length and dry mass of roots and shoots. The dose of $100 \mathrm{~g} \mathrm{~kg}^{-1}$ promoted reductions in the length of the aerial part and symptoms of nutritional deficiency caused by excess aluminum, iron and sodium in the sludge. For safe use, we recommend the dose of $10 \mathrm{~g} \mathrm{~kg}^{-1}$ of the ETA sludge compound.

Keywords: phitotoxicity, water sludge, reuse

\section{INTRODUÇÃO}

A produção de água potável em quantidade suficiente para atender a demanda nos centros urbanos têm sido cada vez mais desafiante para a Estação de Tratamento de Água (ETA). Pois, a qualidade ambiental do entorno dos rios encontra-se cada vez mais degradados e poluídos, o que implica no uso de mais produtos químicos para seu tratamento $[1,2]$.

O processo convencional de potabilização na ETA, durante a etapa de coagulação e floculação utiliza o sulfato de alumínio e ferro e, na decantação é realizada a remoção das partículas sólidas que decantam nas lagoas de secagem. Esse resíduo conhecido como Lodo de Estação de Tratamento de Água (LETA) é constituído por uma massa de partículas orgânicas e inorgânicas, densa e viscosa, apresenta hidróxidos de alumínio, partículas como silte e argila, coloides coloridos e microrganismos como o plâncton $[3,4]$. 
É classificado como um resíduo sólido classe II A - não inerte, sendo necessário ser tratado e disposto de acordo com as recomendações para resíduos sólidos, ou seja, deve ser minimizado, utilizado e/ou reciclado de maneira ambientalmente correta segundo a Lei 12.305, da Política Nacional de Resíduos Sólidos [5]. A disposição mais usual do LETA é em aterros sanitários, no entanto, algumas empresas contrariam a legislação e dispõem seus resíduos nos rios de captação, o que implica em crime ambiental, de acordo com a Lei $n^{\circ}$ 9.605/98, a qual estabelece penalizações $[6,7]$.

A disposição inadequada do LETA pode ocasionar o aumento na concentração de metais, como alumínio ( $\mathrm{Al}$ ) e ferro ( $\mathrm{Fe}$ ), o aumento da turbidez, redução de oxigênio disponível que leva a condições anaeróbias, produzindo odores, crescimento excessivo de algas e mortalidade de peixes, além do assoreamento dos corpos receptores pelo aumento de sólidos sedimentáveis [8].

Diversas alternativas vêm sendo propostas para a recuperação e/ou reutilização do LETA, dentre elas a utilização em solo agricultáveis. Alguns trabalhos citam o uso benéfico do LETA na recuperação de áreas degradadas e em solos agriculturáveis em consorciamento com o lodo de esgoto [9]. Em contrapartida, Ferreira et al. (2017) [10] relata que o LETA ocasiona a compactação do solo e por esse motivo não recomenda a aplicação na sua forma in natura. Os resíduos da indústria canavieira, como a vinhaça e o bagaço de cana-de-açúcar podem servir de matéria prima na elaboração de um composto associado ao LETA para reduzir os efeitos negativos [11].

Os ensaios ecotoxicológicos padronizados pela Associação Brasileira de Normas Técnicas (ABNT) utilizam espécies padronizadas como ferramenta adicional de caracterização, permitindo avaliar os efeitos das substâncias no solo e no crescimento das plantas [11, 12]. Partindo dessa premissa, a presente pesquisa objetivou avaliar a toxicidade do lodo gerado em ETA associado ao bagaço e vinhaça de cana-de-açúcar na germinação e crescimento inicial de Zea mays L.

\section{MATERIAL E MÉTODOS}

O experimento foi conduzido no Centro de Energia Nuclear na Agricultura - CENA, Universidade de São Paulo/USP, localizado na cidade de Piracicaba, São Paulo, Brasil, com coordenadas geográficas $22^{\circ} 42^{\prime} \mathrm{S}$ e $47^{\circ} 38^{\prime} \mathrm{W}$, altitude de $545 \mathrm{~m}$, clima subtropical, com verão quente e inverno seco, temperatura média anual de $22^{\circ} \mathrm{C}$ segundo a classificação de Köppen [13].

O LETA foi coletado na ETA - Capim Fino no município de Piracicaba, São Paulo, Brasil. A vinhaça e o bagaço de cana-de-açúcar foram cedidos pela usina Iracema do grupo de usinas São Martinho, do município de Iracemápolis, São Paulo, Brasil. Os materiais foram estocados em embalagens de polietileno e armazenado em câmara fria a $4^{\circ} \mathrm{C}$.

Foi elaborada uma mistura utilizando a proporção de 1:2 (LETA/Bagaço). A relação foi feita com base na matéria seca de lodo e bagaço, a umidade foi corrigida com a adição de vinhaça para $60 \%$. O composto foi inoculado com Pleurotus sajor-caju para intensificar o processo de degradação dos materiais, além de, contribuir na remediação de substâncias potencialmente tóxicas [7]. Para tanto, utilizou-se a metodologia de Bononi et al. (1995) [14] para obtenção dos inóculos do fungo e foi compostada a $28^{\circ} \mathrm{C}$ por 60 dias. A elaboração da mistura, tempo de compostagem e a escolha da espécie de $P$. sajor-caju, foi em razão dos resultados obtidos anteriormente por Bitencourt et al. (2020a) [7]. A análise química do composto obtido referente aos atributos de fertilidade foi realizada conforme a metodologia descrita no manual de métodos analíticos oficiais para fertilizantes e corretivos IN 28 SP-5189-6 [15] (Tabela 1).

Amostras de solo do tipo Latossolo Vermelho distrófico típico [16] foram coletadas na camada de 0-30 cm, em uma área do campo experimental da Escola superior de Agricultura "Luiz de Queiroz" (Esalq/USP) a $500 \mathrm{~m}$ da rodovia Luiz de Queiroz (saída para Campinas). O solo foi seco ao ar livre, seguido de peneiramento manual (malha $3 \mathrm{~mm}$ ). Uma subamostra foi analisada quanto sua fertilidade pelo laboratório de análises Pirasolo (Tabela 2). A acidez do solo foi corrigida pelo método da elevação da saturação por bases para 70\%, de acordo com as recomendações de Van Raij et al. (1996) [17], utilizando-se carbonato de cálcio (reagente analítico) como corretivo de acidez. 
Tabela 1: Caracterização do composto obtido ao final da compostagem utilizando o lodo gerado na Estação de Tratamento de Água - Capim Fino, Piracicaba - SP.

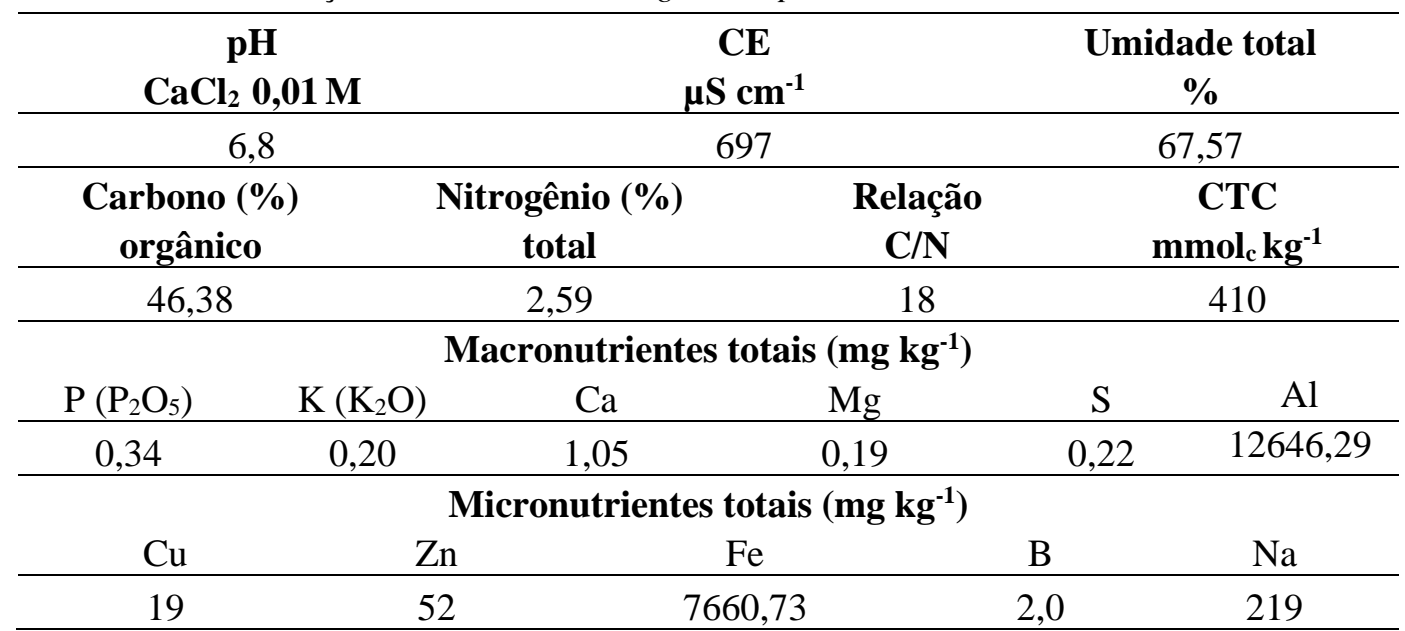

pH = potencial hidrogeniônico; $C E=$ condutividade elétrica; $C T C=$ capacidade de troca catiônica; $P=$ fósforo disponível extraído por Melich-1; K= potássio; $\mathrm{Ca}=$ cálcio; $\mathrm{Fe}=$ ferro; $\mathrm{Mg}=$ magnésio; $\mathrm{S}=$ enxofre; $C u=$ cobre $; M n=$ manganês $; A l=$ alumínio $; Z n=$ zinco $; B=$ boro $; N a=$ sódio, $F e=$ ferro e $A l=$ alumínio quantificados por espectrometria de emissão optica.

Tabela 2: Atributos químicos do solo coletado na Esalq/USP, Piracicaba-SP.

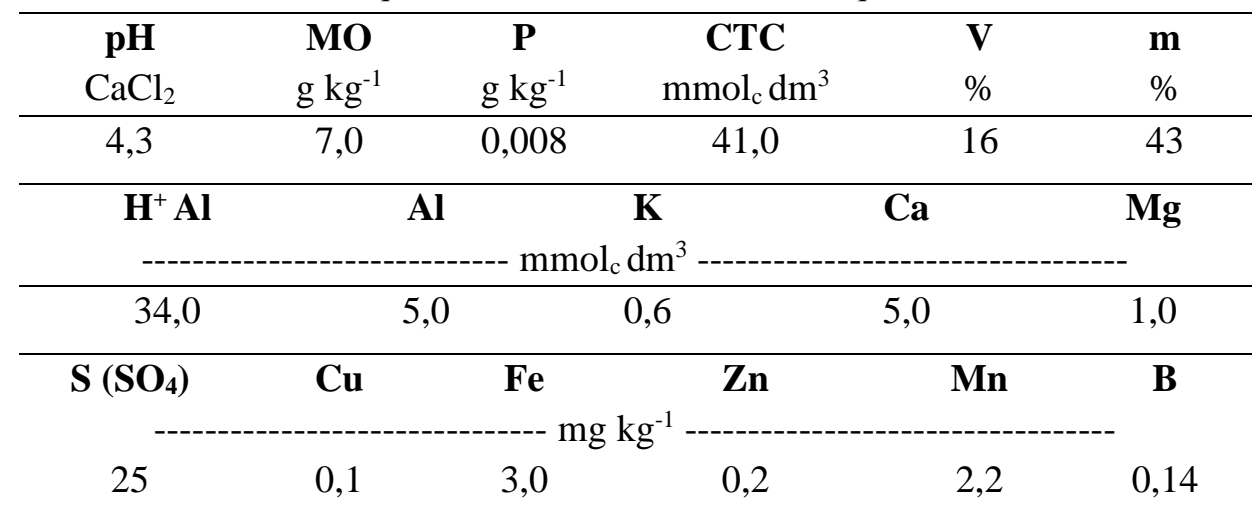

pH = potencial hidrogeniônico; $M O=$ matéria orgânica; $P=$ fósforo $;$ CTC = capacidade de troca catiônica; $V=$ saturação de bases; $m=$ saturação por alumínio; $H^{+} A l=$ acidez trocável; $A l=$ alumínio; $K=$ potássio; $C a=$ cálcio; $M g=$ magnésio $;=$ enxofre; $C u=$ cobre; ; Fe=ferro; $Z n=$ zinco; $M n=$ manganês; $B=$ boro.

O composto a base de LETA foi incorporado ao solo nas doses de $0 ; 1 ; 10$ e $100 \mathrm{~g} \mathrm{~kg}^{-1}$ (composto/solo) na base seca, em vasos com capacidade de $2 \mathrm{~kg}$. O controle é constituído pela dose zero, ou seja, sem aplicação do composto, foi utilizado como testemunha apresentando as condições ideais para o desenvolvimento das plântulas e, sendo fundamental para a comparação com as demais doses para a quantificação dos efeitos tóxicos. Foram semeadas 10 sementes de Z. mays híbrido 2B433Hx da Dow Agrosciences em cada vaso. A porcentagem e o índice de velocidade de emergência foram avaliados por meio da contagem diária das plantas que emergiram durante os sete primeiros dias. Após esse período, foi realizado o desbaste de todos os tratamentos, de forma aleatória, mantendo cinco plântulas em cada vaso.

O delineamento experimental utilizado foi inteiramente casualizado com quatro repetições. Utilizou-se quatro doses do composto a base de LETA, em cada vaso foram mantidas cinco plantas, ou seja, a parcela foi constituída por cinco plantas, totalizando 80 unidades experimentais.

O experimento foi realizado com base na norma ABNT NBR ISO 11269-2 [12] em condições de casa de vegetação com temperatura aproximada de $30^{\circ} \mathrm{C}$. A umidade do solo foi mantida em $50 \%$ da capacidade de retenção de água por meio da pesagem dos vasos e adição de água conforme metodologia descrita na norma ISO 11269-1 [18]. 
Após 14 dias da realização do desbaste, totalizando 21 dias da semeadura, as plantas foram removidas dos vasos, lavadas em água e avaliados os seguintes parâmetros: comprimento e biomassa seca das raízes e parte aérea.

Para a obtenção do comprimento foi utilizada uma régua milimetrada e para a massa seca, as raízes e a parte aérea foram separadas e secas em estufa de aeração forçada a $60^{\circ} \mathrm{C}$ por 16 horas e, pesadas em balança analítica.

Os dados foram submetidos a análise de variância (teste F) e regressão utilizando o programa estatístico SISVAR [19], de modo que o modelo escolhido foi aquele que melhor se ajustou aos dados obtidos.

\section{RESULTADOS E DISCUSSÃO}

A aplicação do composto de LETA nas diferentes doses influenciou nas variáveis: índice de velocidade de emergência (IVE); crescimento de raiz (CR) e de parte aérea (CPA) promovendo diferenças significativas $(\mathrm{p}<0,05)$ (Tabela 3$)$.

Tabela 3: Resumo da análise de variância para índice de velocidade de emergência (IVE); porcentagem de emergência (PE); comprimento de raiz (CR) e da parte aérea (CPA); massa seca de raiz (MSR) e parte aérea (MSPA) de Zea mays L. submetida a diferentes doses (0; 1,0; 10; $\left.100 \mathrm{~g} \mathrm{~kg}^{-1}\right)$ de composto a base de lodo gerado em Estação de Tratamento de Água (ETA).

\begin{tabular}{lccccccc}
\hline FV & GL & IVE & PE & CR & CPA & MSR & MSPA \\
\hline Doses & 3 & $9,66^{*}$ & 1,70 & $7,61^{*}$ & $5,47^{*}$ & 0,30 & 3,20 \\
Regressão linear & 3 & 3,43 & 2,57 & $22,25^{*}$ & $15,93^{*}$ & 0,003 & 1,44 \\
Regressão quadrática & 3 & 1,06 & 1,50 & 0,567 & 0,210 & 0,194 & $7,68^{*}$ \\
Erro & 12 & & & & & & \\
\hline
\end{tabular}

*significativo $(p<0,05)$. FV= Fonte de variação; GL= Grau de liberdade

O IVE apresentou diferença significativa $(\mathrm{p}<0,05)$ somente para doses. A dose de $100 \mathrm{~g} \mathrm{~kg}^{-1} \mathrm{do}$ composto de LETA reduziu a velocidade de emergência (Figura 1).

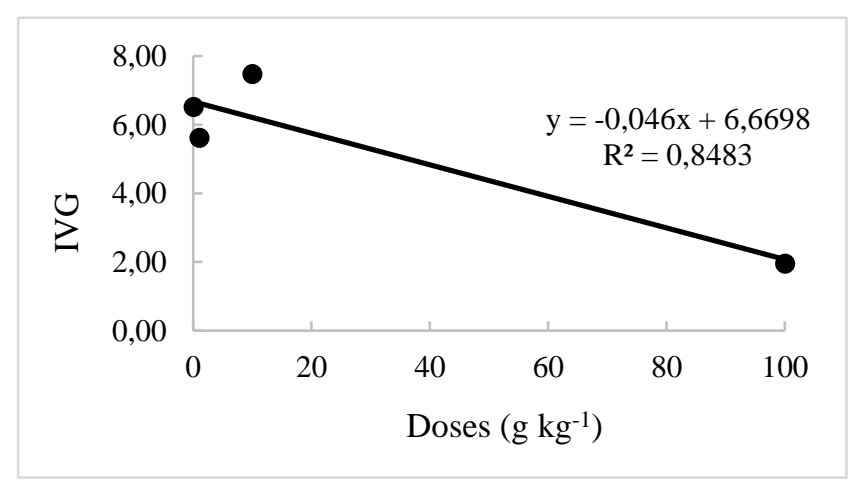

Figura 1: Índice de velocidade de emergência (IVE) de Zea mays L. cultivada em solo com diferentes doses $\left(\mathrm{g} \mathrm{kg}^{-1}\right)$ de composto a base de lodo de Estação de Tratamento de Água (LETA).

A redução no índice de velocidade de emergência (IVE) é um parâmetro para verificar interferências de toxicidade sobre as sementes e consequentemente sobre as plântulas [20]. As sementes que apresentaram um tempo maior para emergir plântulas, podem originar plantas menores com anomalias, mais sensíveis a estresses e predação [21]. Entretanto, a porcentagem de 
emergência não foi afetada, sendo superior a $80 \%$ em todas as doses aplicadas, não apresentando diferença estatística (Figura 2).

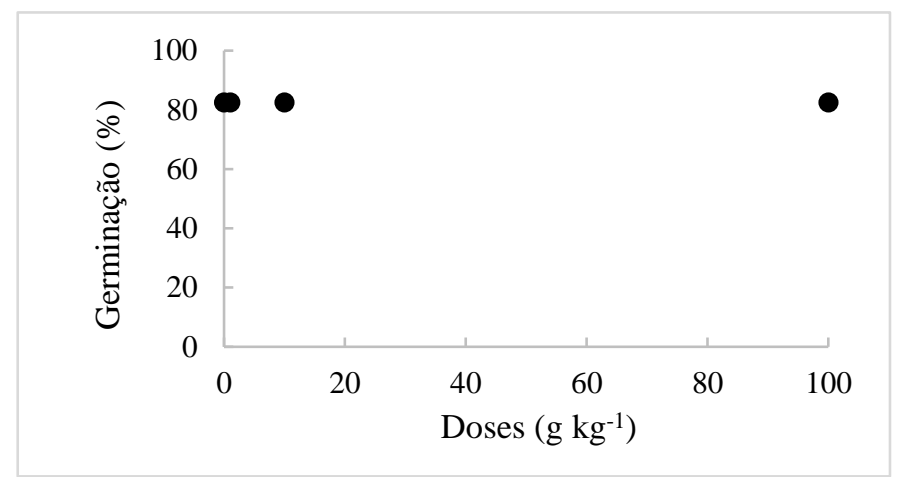

Figura 2: Porcentagem de emergência (PE) de Zea mays L. cultivada em solo com diferentes doses $\left(\mathrm{g} \mathrm{kg}^{-1}\right)$ de composto a base de lodo de Estação de Tratamento de Água (LETA).

Os resultados são semelhantes aos obtidos por Messias (2013) [22] e Santos (2014) [23] que também testaram o LETA da mesma ETA e obtiveram pelo menos $50 \%$ da emergência de milho após o $5^{\circ}$ dia da semeadura. Um experimento similar utilizando plantas de milheto e feijão guandu, verificou uma média de $80 \%$ de germinação [7].

O crescimento vegetal tanto de raiz como de parte aérea foi estatisticamente diferente. A aplicação da mistura de LETA na dose de $100 \mathrm{~g} \mathrm{~kg}^{-1}$ promoveu aumento linear significativo $(\mathrm{p}<0,05)$ no comprimento de raiz $(\mathrm{CR})$, com resultados superiores ao tratamento sem LETA, sendo na dose de $100 \mathrm{~g} \mathrm{~kg}^{-1}$ estimado um aumento de 26,96\% em relação ao controle (Figura 3). E essas diferenças foram visualmente verificadas entre as dosagens aplicadas (Figura 4).

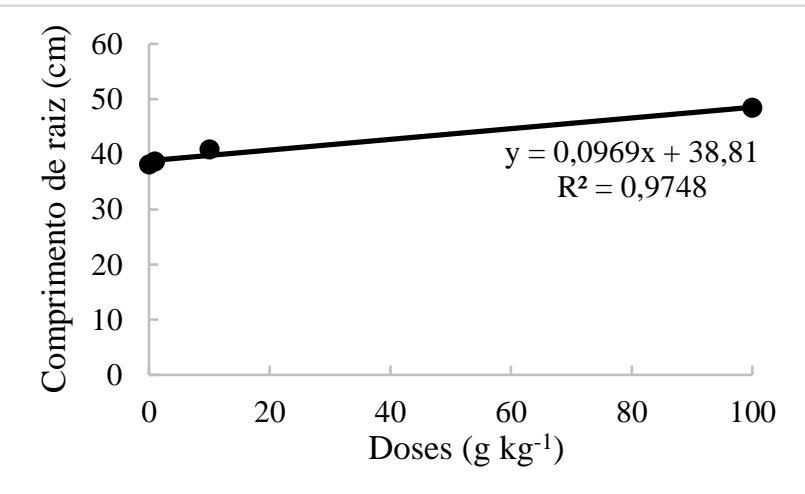

Figura 3: Comprimento de raiz (CR) de Zea mays L. cultivada em solo com diferentes doses $\left(\mathrm{g} \mathrm{kg}^{-1}\right)$ de composto a base de lodo de Estação de Tratamento de Água (LETA). 


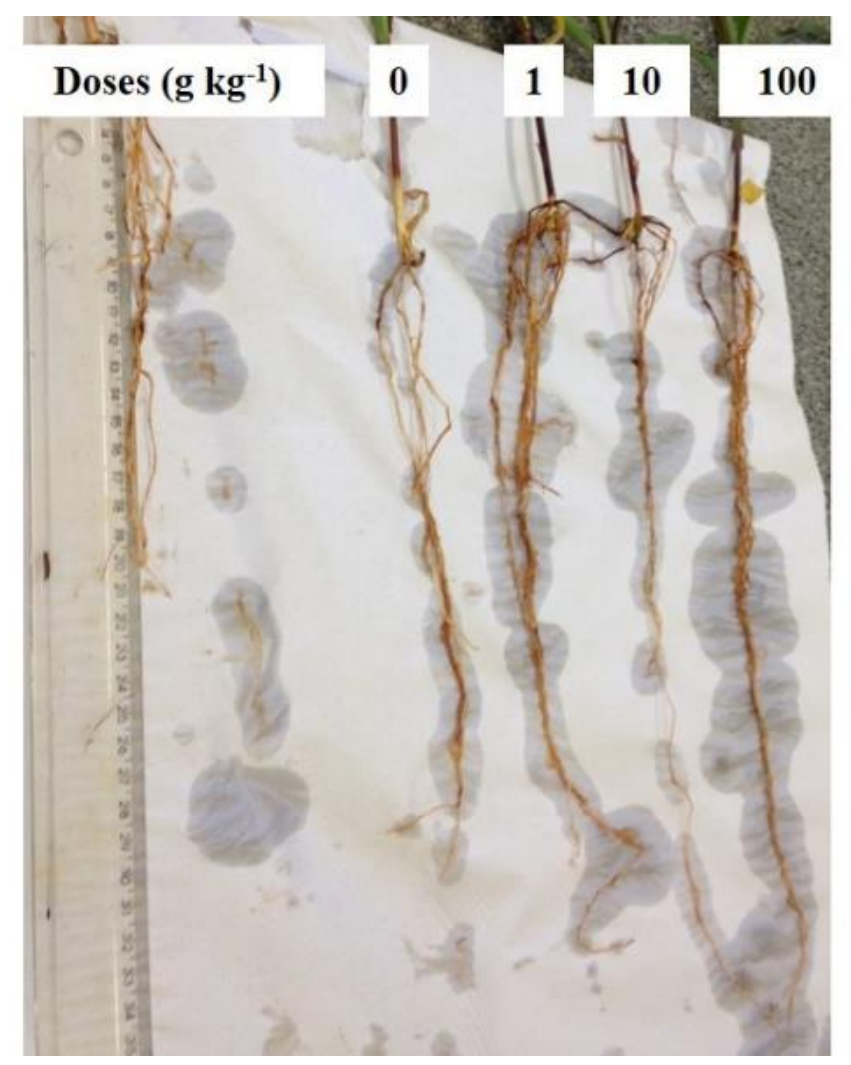

Figura 4: Raízes de Zea mays L. após 21 dias de crescimento em solo com aplicação de diferentes doses ( $g$ $\mathrm{kg}^{-1}$ ) de composto a base de lodo gerado em Estação de Tratamento de Água (LETA).

O comprimento de parte aérea (CPA) enquadrou-se em um modelo de regressão linear decrescente. Ou seja, a dose de $100 \mathrm{~g} \mathrm{~kg}^{-1}$ de LETA reduziu o crescimento em altura das plantas em $21,44 \%$ em comparação com o controle (Figura 5).

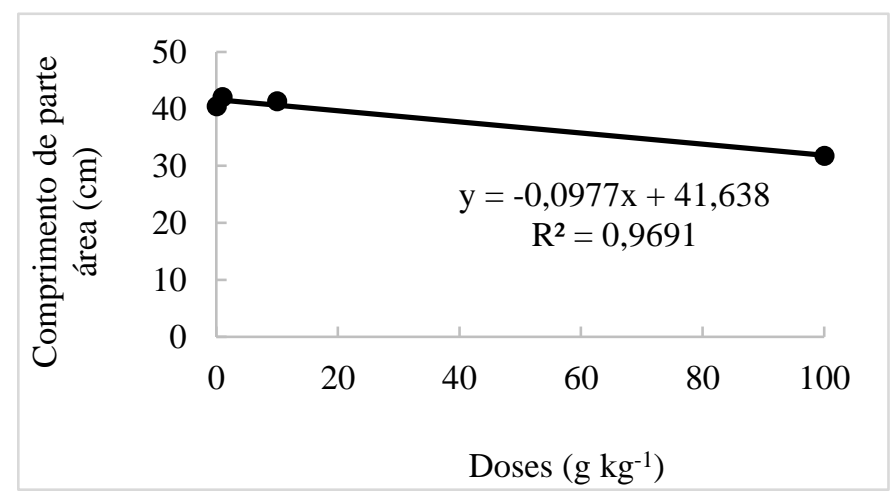

Figura 5: Comprimento de parte aérea (CPA) de Zea mays L. cultivada em solo com diferentes doses ( $g$ $\mathrm{kg}^{-1}$ ) de composto a base de lodo de Estação de Tratamento de Água (LETA).

Na figura 6 estão apresentados os vasos das plantas nas diferentes doses de LETA aplicado ao solo. Visualmente na dose de $100 \mathrm{~g} \mathrm{~kg}^{-1}$ as plantas apresentaram-se menores em comparação com as demais dosagens. 

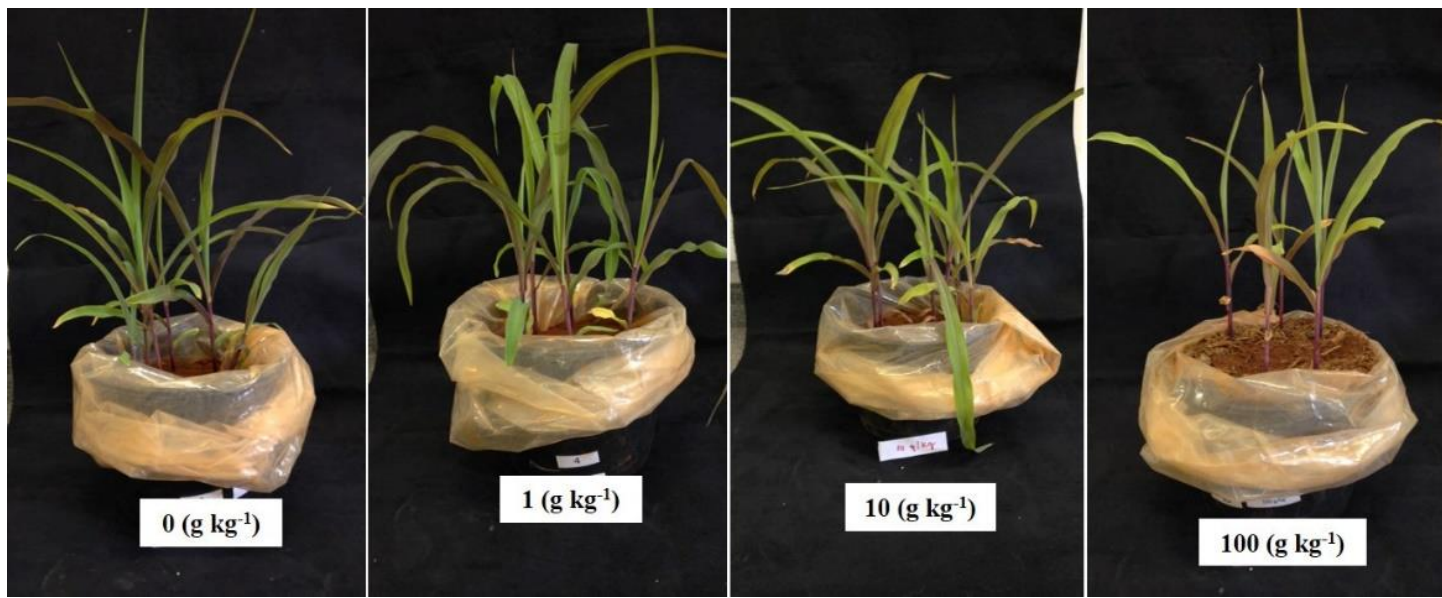

Figura 6: Plantas de Zea mays L. após 21 dias de crescimento em solo com aplicação de diferentes doses $\left(\mathrm{g} \mathrm{kg}^{-1}\right)$ de composto a base de lodo gerado em Estação de Tratamento de Água (LETA).

Não foi verificada diferença estatística para massa seca nas raízes (MSR) de Z. mays em função das doses testadas (Figura 7).

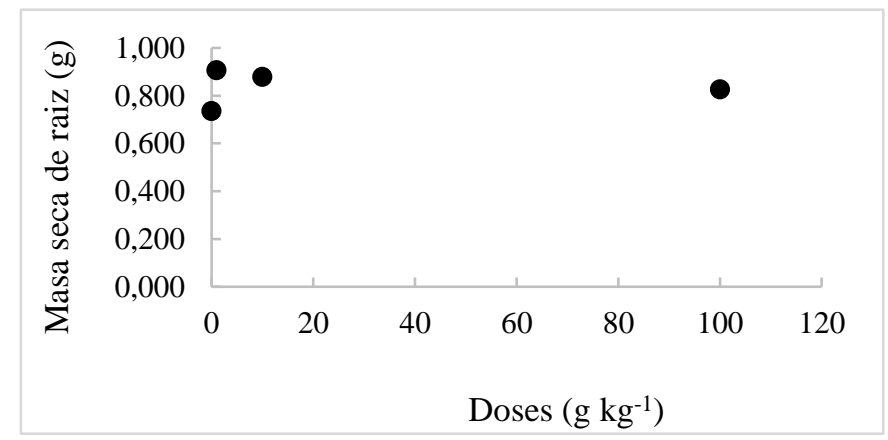

Figura 7: Massa seca de raiz (MSR) de Zea mays L. cultivada em solo com diferentes doses $\left(\mathrm{g} \mathrm{kg}^{-1}\right)$ de composto a base de lodo de Estação de Tratamento de Água (LETA).

A massa seca da parte aérea de $Z$. mays $L$. se ajustou em um modelo de regressão quadrática. A dosagem de $10 \mathrm{~g} \mathrm{~kg}^{-1}$ de LETA promoveu o aumento de 41,97\% dessa variável em comparação com a dose sem LETA (controle). As demais dosagens, sendo 1,0 e $100 \mathrm{~g} \mathrm{~kg}^{-1}$ de LETA apresentaram a massa seca similar ao tratamento controle (Figura 8).

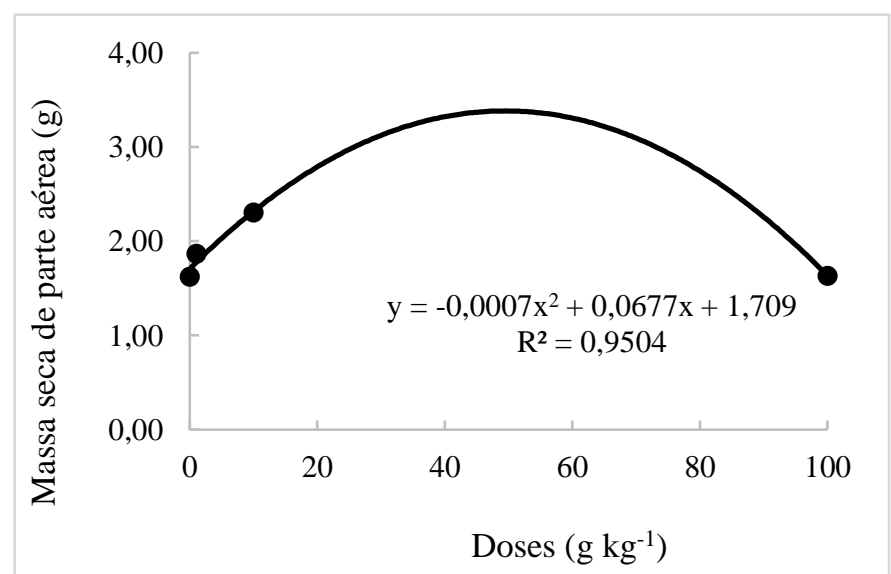

Figura 8: Massa seca de parte aérea (MSPA) de Zea mays L. cultivada em solo com diferentes doses ( $\mathrm{g} k \mathrm{~g}$ $\left.{ }^{1}\right)$ de composto a base de lodo de Estação de Tratamento de Água (LETA). 
De acordo com Madejón et al. (2015) [24] a germinação de sementes e o crescimento radicular são considerados parâmetros essenciais para a avaliação da fitotoxicidade a compostos orgânicos. Os resultados indicaram que o composto de LETA quando aplicado na dose de $100 \mathrm{~g} \mathrm{~kg}^{-1}$ afetou negativamente no crescimento de milho, reduzindo as variáveis porcentagem de emergência, índice de velocidade emergência e comprimento de parte aérea.

Um experimento utilizando chorume de aterro sanitário na germinação de $Z$. mays verificou a diminuição no comprimento de raiz e de parte área quando utilizada a concentração de $100 \%$ [25].

A aplicação in natura do LETA associado ao lodo de ETE foi testada em plantas de milheto. Não houve diferenças significativas para o uso do LETA quando avaliado para fins de melhoria de fertilidade de solo [9]. Resultados similares foram citados por Ferreira et al. (2017) [10] que utilizou solo adubado com LETA e não observou diferenças significativas no desenvolvimento do capim Tifton. Com base nas observações, a aplicação do LETA no seu estado bruto não é recomendada. Ressalta-se a importância de agregar materiais para melhorar a estruturação e fertilidade do mesmo.

O lodo da mesma ETA desse estudo foi aplicado em substrato comercial, e foram verificadas melhorias na concentração de 50\% de lodo, estimulando o crescimento das raízes de milho [22]. O que sugere que o substrato comercial apresenta material estruturante na sua composição, tenha evitado a compactação do solo em função da composição pastosa do LETA.

Em um estudo semelhante, Santos (2014) [23] aplicou uma mistura de LETA tratado em condições laboratoriais por 15 dias com $P$. sajor-caju em vasos contendo substrato comercial e, obteve efeitos positivos no crescimento das plantas de milho e girassol.

Bitencourt et al. (2020a) [7] utilizou uma mistura de LETA, bagaço e vinhaça compostada por 20 e 60 dias com duas espécies de fungos ( $P$. sajor-caju e P. ostreatus) em plantas de milheto e feijão guandu. As misturas testadas não interferiram no crescimento de milheto, apresentando performance semelhante ao cultivo em somente solo. Resultados diferentes para o feijão guandu foram obtidos, as melhores respostas foram verificadas nas misturas compostadas por 60 dias com ambas as espécies de fungos.

A toxicidade depende da concentração e constituição química das substâncias às quais as plantas são expostas. Além disso, o tempo de exposição precisa ser considerado [26]. A interferência das substâncias afeta inicialmente a germinação e, posteriormente o crescimento e desenvolvimento das raízes. As raízes desempenham funções de sustentação, absorção de água e nutrientes, por esse motivo, os poluentes, elementos químicos e agrotóxicos são também absorvidos e, dependendo da concentração podem afetar o desenvolvimento das plantas [27].

As plantas apresentaram redução no comprimento de parte aérea e o aumento no crescimento das raízes que podem ser indicativos de estresse. Além disso, observou-se o amarelecimento e necrose nas folhas (Figura 6). Com base na análise do composto a base de LETA (Tabela 1) foram verificados elevados teores de alumínio $(\mathrm{Al})$, ferro $(\mathrm{Fe})$. Esses elementos químicos em excesso são provenientes do processo de coagulação e floculação na ETA, que são sedimentados formando o LETA.

A toxicidade ao $\mathrm{Al}$ é relatada somente em condições de $\mathrm{pH}$ abaixo de 5,5 devido a solubilidade dos íons $\mathrm{Al}^{3+}$ em meio ácido. De acordo com Bitencourt et al. (2011) [28], ela é induzida pelos íons $\mathrm{Al}^{3+}$ no metabolismo celular do $\mathrm{Ca}^{2+}$. O sintoma mais evidente da toxicidade ao $\mathrm{Al}$ é a redução no comprimento e engrossamento das raízes em plantas sensíveis, aliados as alterações fisiológicas e bioquímicas, que podem causar grandes perdas na produtividade. Nesse caso, as plantas apresentaram aumento no crescimento das raízes, o que não condiz com o primeiro sintoma ocasionado por toxidez ao $\mathrm{Al}[28,29]$.

Miguel et al. (2010) [29] cita um estudo de tolerância ao alumínio em Brachiaria ruziziensis, que observou o aumento das raízes nas maiores concentrações de alumínio, sendo de 60 ppm, fato esse, similar os resultados obtidos nesse trabalho na dose de $100 \mathrm{~g} \mathrm{~kg}^{-1}$ do composto de LETA, onde a concentração de $\mathrm{Al}$ é superior aos demais tratamentos, contrariando os relatos da maioria dos estudos a respeito desse assunto. Além disso, as raízes apresentaram-se amareladas, grossas, quebradiças e pouco volumosas, sintomas similares também foram observados na maior concentração, as raízes cresceram mais em comprimento do que em diâmetro, apresentando poucas raízes secundárias e uma principal bastante comprida (Figura 4).

Outros sintomas que são importantes de serem evidenciados são com relação ao aspecto das folhas das plantas de milho nas diferentes doses. As folhas na dose de $100 \mathrm{~g} \mathrm{~kg}^{-1}$ apresentaram-se 
mais amareladas e arroxeadas nas bainhas e margens do limbo. $\mathrm{O}$ fato de estarem mais amareladas, pode ser referente a presença de Al na solução do solo que pode interferir na biossíntese de clorofila, além disso, o arroxeamento das folhas, pode indicar deficiência de fósforo [29].

Outro fato relevante, é com relação as elevadas concentrações de Fe citadas no composto a base de LETA, que podem exibir sintomas de toxicidade como amarelecimento e/ou bronzeamento das folhas e escurecimento das raízes, indicando sintomas de deficiência nutricional. Além do mais, o excesso de Fe pode induzir a formação de espécies reativas de oxigênio que ocasionam em reduções no crescimento e produtividade [29].

A toxicidade por Fe é citada em arroz (Oryza sativa L.) em sistemas alagados, devido a quantidade excessiva de íons ferrosos $\left(\mathrm{Fe}^{2+}\right)$ ocasionados pela diminuição de óxidos de ferro em solos alagados. O nível crítico de toxicidade de Fe depende de fatores como a espécie, período vegetativo e estado nutricional [30, 31].

O alumínio conjugado ao excesso de ferro pode desencadear um desequilíbrio nutricional das plantas que, consequentemente apresentaram sintomas de estresse, além disso, observa-se que a concentração de sódio (Na) no composto está elevada (Tabela 1), fato esse que pode justificar os sintomas relacionados a deficiência nutricional e a redução no potencial osmótico da água no solo, promovendo a redução de absorção de água pelas raízes, o que evidencia o aumento do crescimento radicular em busca de água em profundidade na dose de $100 \mathrm{~g} \mathrm{~kg}^{-1}$ [32].

$\mathrm{O}$ excesso de Na no solo, além de alterar os atributos físicos e químicos, ocasiona na redução generalizada do crescimento vegetal. Segundo Filho et al. (2016) [32] a parte aérea dos vegetais é mais sensível à toxidez de salinidade do que o sistema radicular, tanto em experimentos de longa e de curta duração. Nesse caso, a área foliar é primordial no estabelecimento e desenvolvimento de qualquer cultura, estando diretamente relacionada com a absorção de luz, fato esse que, está vinculado a síntese de fotoassimilados, além de outras características fisiológicas [33].

Os resultados iniciais apontam positivamente para a utilização do LETA agregado a vinhaça e bagaço de cana de açúcar no cultivo de plantas de milho até a dose $10 \mathrm{~g} \mathrm{~kg}^{-1}$. Contudo, a dose de $100 \mathrm{~g} \mathrm{~kg}^{-1}$ provocou sintomas que podem ser oriundos de deficiência nutricional, ocasionado pelo desbalanço dos nutrientes em função do excesso de $\mathrm{Al}, \mathrm{Fe}$ e Na. Por esse motivo não sugerimos seu uso até a obtenção de mais respostas. Para tanto, recomendamos mais pesquisas relacionados a avaliação nutricional das plantas cultivadas nessa dosagem por um maior período.

\section{CONCLUSÃO}

O teste ecotoxicológico utilizando sementes de milho revelou ser uma boa ferramenta para verificação dos efeitos do composto a base de lodo gerado em Estação de Tratamento de Água (LETA). A dose de $100 \mathrm{~g} \mathrm{~kg}^{-1}$ promoveu reduções no comprimento de parte aérea, aumento no crescimento das raízes que podem ter ocasionado sintomas de deficiência nutricional e de estresse salino. Para o uso seguro, recomendamos a dose de $10 \mathrm{~g} \mathrm{~kg}^{-1}$ do composto a base de LETA.

\section{AGRADECIMENTOS}

Ao Conselho Nacional de Desenvolvimento Científico e Tecnológico (CNPq) pela concessão de bolsa de estudos a autora do trabalho.

\section{REFERÊNCIAS BIBLIOGRÁFICAS}

1. Silva CA, Silveira C, Silva FA, Klen MRF, Bergamasco R. Classificação dos lodos formados durante o processo de coagulação/floculação da água com os coagulantes PAC e Moringa Oleifera. Engevista. 2012;14(3):302-309, doi: 10.22409/engevista.v14i3.380

2. Monteiro RT, Silva GH, Messias TG, Queiroz SCN, Assalin MR, Cassoli DR, Alves CHR, Ferreira AC, Blaise C. Chemical and ecotoxicological assessments of water samples before and after being processed by a Water Treatment Plant. Rev Ambiente \& Água. 2014;9(1):6-18, doi: 10.4136/ambi-agua.1292 
3. Lucon IM, Berton RS, Coscione AR. Adsorção de fósforo em latossolo tratado com lodo de estação de tratamento de água. Rev AIDIS de Ingenieria y Ciencia Ambientales: investigación, desarrollo y prática. 2017;10(3):317-326, doi: 10.22201/iingen.0718378xe.2017.10.3.56547

4. Moreira VTG, Paiva GS de, Soares AFS. Lodo de estação de tratamento de água (LETA): resíduo ou insumo? Rev Petra. 2017;3(1):17-37.

5. Brasil. Lei ${ }^{\circ} 12.305$, de 2 de agosto de 2010. Dispõe sobre a política nacional de resíduos sólidos. Diário Oficial da União, Brasília. 03 ago 2010;147(Seção 1):3.

6. Molina T. Caracterização e tratamento de água de lavagem de filtros de ETA com o uso de polímeros sintéticos e amido de batata. Rev Eng Tecnol. 2010;2(3):28-44.

7. Bitencourt GA, de Souza G, Frazão JJ, Apolari JPA, Monteiro, RTR. Uso do lodo de ETA no crescimento de feijão guandu e milheto. Rev Biol Ciên Terra. 2020;20(1):10-16.

8. Motta Sobrinho MA da, Tavares RG, Arruda VCM de, Correa MM, Pereira LJR. Geração, tratamento e disposição final dos resíduos das estações de tratamento de água do estado de Pernambuco. Engenharia Sanitária e Ambiental. 2019 24(4):761-771.

9. Bittencourt S, Serrat BM, Aisse MM, Marin LMKS, Simão CC. Aplicação de lodos de estações de tratamento de água e de tratamento de esgoto em solo degradado. Eng Sanit Amb [online]. 2012;17(3):315-324, doi: 10.1590/S1413-41522012000300008

10. Ferreira ACS, Silva JBG, Pereira RO, Oliveira APS. Avaliação do desenvolvimento do capim Tifton cultivado em latossolo adubado com lodo de ETA. Rev Int Ciên. 2017;7(1):64-83, doi: 10.12957/ric.2017.26466

11. Bitencourt GA., Vaso LM, Gomez ALC, Souza TT, Pradebon BS, Montanhez BE. Ecotoxicologia de biofertilizante bovino e ovino. Fórum Ambiental da Alta Paulista. 2020;16(3):96-107, doi: $10.17271 / 1980082716320202388$

12. Associação Brasileira de Normas Técnicas - ABNT. NBR ISO 11269-2. Qualidade do solo - determinação dos efeitos de poluentes na flora terrestre. 2. ed. Rio de Janeiro: ABNT; 2014. 23 p.

13. Alvares CA, Stape JL, Sentelhas PC, Gonçalves JLM, Sparovek G. Köppen's climate classification map for Brazil. Meteorol Zeitschrift. 2013;22(6):711-728. doi: 10.1127/0941-2948/2013/0507

14. Bononi VLR, Capelari M, Maziero R, Trufem SF, editores. Cultivo de cogumelos comestíveis. São Paulo: Ícone; 1995. 209 p.

15. Brasil. Ministério da Agricultura, Pecuária e Abastecimento. Manual de métodos analíticos oficiais para fertilizantes e corretivos. Brasília (DF): Ministério da Agricultura, Pecuária e Abastecimento; 2013. 240 p.

16. Embrapa. Sistema brasileiro de classificação de solos. 3. ed. Rio de Janeiro: Embrapa Solos; 2013. 353 p.

17. Van Raij B, Cantarella H, Quaggio JA, Furlani AMC. Recomendação de adubação e calagem para o Estado de São Paulo. 2. ed. Campinas: IAC; 1996. 285 p. (Boletim Técnico, 100).

18. International Organization for Standardization. ISO 11269-1: Soil quality - Determination of the effects of pollutants on soil flora - Part 1: Method for the measurement of inhibition of root growth. Geneva: ISO; 1993.

19. Ferreira DF. SISVAR: a computer analysis system to fixed effects split plot type designs. Rev Bras Biom. 2019;37(4):529-535, doi: 10.28951/rbb.v37i4.450

20. Gusman GS, Yamagushi MQ, Vestena S. Potencial alelopático de extratos aquosos de Bidens pilosa L., Cyperus rotundus L. e Euphorbia hterophylla L. Iheringia, Série Botânica. 2011;66(1):87-98.

21. de Oliveira AKM, Ribeiro JWF, Matias R, de Gusmão DH, Pereira KCL. Alelopatia de extratos de diferentes órgãos de mulungu na germinação de alface. Hortic Bras. 2012;30:480-483. doi: 10.1590/S0102-05362012000300020.

22. Messias TG. Avaliação ecotoxicológica de lodo gerado por estação de tratamento de água [tese]. Piracicaba (SP): Centro de Energia Nuclear na Agricultura, Universidade de São Paulo; 2013. 163 p.

23. Santos JRP. Potencial de biodegradação de resíduos por Pleurotus spp. [dissertação]. Piracicaba (SP): Escola Superior de Agricultura "Luiz de Queiroz", Universidade de São Paulo, Piracicaba; 2014. 110 p.

24. Madejón P, Cantos M, Jiménez-Ramos MC, Marañón T, Murillo JM. Effects of soil contamination by trace elements on white poplar progeny: seed germination and seedling vigour. Environm Monit Assess. 2015;187(11):663-674, doi: 10.1007/s10661-015-4893-8

25. Nascentes AL, Pereira BC, de Pinho CF, da Silva LDB, Zonta E, Ferreira JÁ, Campos JC. Avaliação da toxicidade de lixiviado de aterro sanitário utilizando germinação de sementes de milho. Rev Estudos Ambientais. 2019;21(2):20-30, doi: 10.7867/1983-1501.2019v21n2p20-30

26. Gryczak M, Kilipper TJ, Costa DP, Maccari A. Sementes de Lactuca sativa como bioindicador de toxicidade em resíduos de construção civil. Rev Tecnol Ambiente. 2018;24:233-242, doi: 10.18616/ta.v24i0.4406 
27. Mata JF, Pereira JCS, Chagas JFR, Vieira LM. Germinação e emergência de milho híbrido sob doses de esterco bovino. Amazônia: Ciên Desenv. 2011;6(12):31-40.

28. Bitencourt GA, Chiari L, Laura VA, Valle C, Jank L, Moro JR. Aluminum tolerance on genotypes of signal Grass. Rev Bras Zoot. 2011;40(2):245-250, doi: 10.1590/S1516-35982011000200003

29. Miguel PSB, Gomes FT, Rocha WSD da, Martins CE, de Carvalho CA, de Oliveira AV. Efeitos tóxicos do alumínio no crescimento das plantas: mecanismos de tolerância, sintomas, efeitos fisiológicos, bioquímicos e controles genéticos. CES Rev. 2010;24:12-30.

30. Siqueira-Silva, AI, Silva, LS, Azevedo, AA, Oliva, MA. Iron plaque formation and morphoanatomy of roots from species of resting subjected to excess iron. Ecotox Environm Safety. 2012;78:265-275, doi: 0.1016/j.ecoenv.2011.11.030

31. Jucoski GO, Cambraia J, Ribeiro C, de Oliveira JA, de Paula SO, Oliva MA. Impact of iron toxicity on oxidative metabolism in young Eugenia uniflora L. plants. Acta Physiol Plantarum. 2013;35:1645-1657, doi: 0.1007/s11738-012-1207-4

32. Filho WSS, Gheyi HR, Brito MEB, Nobre RG, Fernandes PD, Miranda RS. Melhoramento genético e seleção de cultivares tolerantes à salinidade. In: Gheyi HR, Dias NS, de Lacerda CF, Gomes Filho E. Manejo da salinidade na agricultura: Estudos básicos e aplicados. Fortaleza (CE): INCTSal - Instituto Nacional de Ciência e Tecnologia em Salinidade; 2016. p. 259-274.

33. Berilli SS, de Sales RA, Pinheiro APB, Pereira LC, Gottardo LE, Berilli APCG. Componentes fisiológicos e crescimento inicial de mudas de palmeira-garrafa em resposta a substratos com lodo de curtume. Rev Sci Agr. 2018;19(1):94-101, doi: 10.5380/rsa.v19i1.54814 